Research Paper:

\title{
Relationship Between Health-Promoting Lifestyle and Self-Care Behaviors in Patients With Heart Failure
}

\author{
Sousan Saadati ${ }^{1} \odot$ Marhamat Farahaninia $^{2^{\star}} \odot$, Mehri Bozorgnezhad $^{3} \odot$, Hamid Haghani $^{4} \odot$ \\ 1. Department of Community Health Nursing, School of Nursing and Midwifery, Iran University of Medical Sciences, Tehran, Iran \\ 2. Nursing Care Research center, School of Nursing and Midwifery, Iran University of Medical Sciences, Tehran, Iran. \\ 3. Department of Medical-Surgical Nursing, School of Nursing and Midwifery, Iran University of Medical Sciences, Tehran, Iran \\ 3. Department of Biostatistics, School of Public Health, Iran University of Medical Sciences, Tehran, Iran.
}

\begin{tabular}{|c|c|}
\hline $\begin{array}{l}\text { Use your device to scan } \\
\text { and read the article online }\end{array}$ & diten: Saadati, S., et al., 2019. Relationship between Health-Promoting Lifestyle and Self-Care Behaviors in Patients with \\
\hline 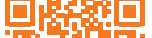 & Heart Failure. Journal of Client-Centered Nursing Care, 5(1), pp. 15-24. http://dx.doi.org/10.32598/jccnc.5.1.15 \\
\hline 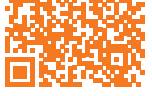 & d of http://dx.doi.org/10.32598/jccnc.5.1.15 \\
\hline
\end{tabular}

(a) 08

Article info:

Received: 15 Jul 2018

Accepted: 03 Nov 2018

Published: 01 Feb 2019

Keywords:

Health-promoting lifestyle, Self-care behaviors, Heart failure

\begin{abstract}
A B S T RA C T
Background: Healthy lifestyle is the mainstay of improving people's health. Also, self-care helps increase the quality of life and maintaining independence. This study aimed to determine the relationship between health-promoting lifestyle and self-care behaviors in patients with heart failure.

Methods: In this predictive correlational study, a total of 200 patients with heart failure were selected by stratified proportionate to size sampling method from the patients referred to cardiac clinics of hospitals affiliated to Iran University of Medical Sciences. The study data were collected by the Health Promoting Lifestyle Profile II (HPLPII) and the European Heart Failure Self-care Behavior (EHFScB) scale. Then, the obtained data were analyzed by ANOVA, the Independent t-test, the Pearson correlation coefficient, and linear regression in SPSS V. 16.

Results: The Mean \pm SD score of health-promoting lifestyle was $120.83 \pm 23.13$; which is lower than the median tool score of 130 . more than half of the subjects $(58.5 \%)$ had an average level of self-care behavior, and their Mean \pm SD score was $34.8 \pm 9.03$. There was a positive and significant correlation between lifestyle and its dimensions with self-care behaviors $(\mathrm{P}<0.001)$. Health responsibility, physical activity, and nutrition were significant in the regression model $(\mathrm{P}<0.05)$ and health responsibility was the most effective one in predicting self-care behavior in patients with heart failure.

Conclusion: According to the findings, health-promoting lifestyle and its dimensions have a positive and significant relationship with self-care behaviors of patients with heart failure. It is recommended that health care providers, planners, and nurses, especially those involved in community health nursing, make every effort to empower patients in assuming responsibility for their care.
\end{abstract}

* Corresponding Author:

Marhamat Farahaninia, MSc.

Address: Nursing Care Research center, School of Nursing and Midwifery, Iran University of Medical Sciences, Tehran, Iran. Tel: +98 (912) 2059958

E-mail: farahaninia.m@iums.ac.ir 


\section{Highlights}

- Heart failure is one of the most common types of heart diseases.

- Heart failure is a chronic disease that affects daily activities and requires long-term care.

- Despite the medical advancements, the long-term prognosis for this disease is still poor.

- Healthy lifestyle reduces the incidence and severity of chronic diseases.

\section{Plain Language Summary}

Chronic diseases account for $60 \%$ of deaths in the world. Nowadays, responding to this demand in the management of chronic diseases is a priority for health care providers. Since the major part of care is on patients, their direct involvement in the process of treatment is very effective in reducing the health costs. This study discusses the relationship between health-promoting lifestyle and self-care behaviors in patients with heart failure. Study results showed that health responsibility was the most effective factor in predicting self-care behavior in patients with heart failure. Thus, patients' empowering to take care of themselves and having a healthy lifestyle are recommended.

\section{Background}

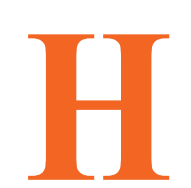

eart failure is among the most prevalent heart disease types (Halmo, Galuszka, Langova, \& Galuszkova, 2015). There are more than 23 million patients with heart failure worldwide, and by 2030 , the incidence of the disease will be increased to $46 \%$; it will reach to 8 million cases only in the United States (Bauersach, Butler, \& Sandner, 2017). In developing countries, $1-2 \%$ of people suffer from heart failure, which is increasing (Hosseini, Reshidi, Vasli, \& Shahsavari, 2016). This illness has the highest mortality rate in the world (Riegel, Lee, \& Dickson, 2011). According to the World Health Organization (WHO) in 2011, 45\% of Iranian people have died due to cardiovascular disease (Mohseni Pouya et al., 2015). Despite the medical advancements, the long-term prognosis for this disease is still poor (Del Gobbo et al., 2015).

Heart failure is a chronic disease that affects day-to-day activities and requires long-term care (Vaillant-Roussel et al., 2014). Due to the changed pattern of diseases from acute to chronic, it is necessary to pay more attention to chronic conditions (Karbaschi, Farsi, \& Siadati, 2010). The care most required for people suffering from chronic diseases is self-care (Pender, Murdaugh, \& Parsons, 2015). Chronic diseases account for $60 \%$ of deaths in the world. Responding to such extensive expected services in the management of chronic diseases is a priority for the health sector. Self-care improves health and the quality of life, patients' satisfaction, rationalizes the use of services, reduces the need for counseling service providers in healthcare settings, and reduces outpatient visits and the use of hospital resources (Ministry of Health and Medical Education, 2014; Rafieifar, Yazdani, \& Moghimi, 2015).

Lots of the financial resources of families and countries are spent on managing health problems (Mahmoudi, Karimlou, Sajadi, \& Mahmoudi, 2014). Most of these expenses are related to the treatment of these patients and the cost of hospitalization, because of their exacerbated condition; many of which are due to poor self-care behaviors (Moser, Dickson, Jaarsma, Lee, Stromberg, \& Riegel, 2012). The major part of care is on patients; thus, their direct involvement in treatment could significantly reduce the costs (Zamanzadeh, Valizadeh, Jamshidi, Namdar, \& Maleki, 2012). Self-care in heart failure, as a decision-making process, includes preservation and management strategies. Self-preservation involves actions that maintain patient' health and functioning through adherence to recommended diets like reduced fluid intake and daily exercise (Graven, Grant, \& Gordon, 2015), and the ability of patients to recognize symptoms and conduct appropriate behavior at the right time (all promote self-care behaviors) (Moser et al., 2012).

Self-care management involves identifying and controlling signs like fluid accumulation by regularly measuring weight and responding through appropriate assistance when symptoms are exacerbated (MacInnes, 2013). Patients with more effective self-care have a sense of self-engagement in the process of care and treatment (Khachian, Seyedoshohadaee, Haqhani \& 
Aghamohammadi, 2016), a feeling of vitality, improved livelihood and health and daily activities capabilities (Bagheri Saweh \& Ashketorab, 2016). The most prevalent chronic diseases are related to various risk factors, such as smoking, inappropriate nutrition, and so on (Paulik, Bóka, Kertész, Balogh, \& Nagymajtényi, 2010).

The increased prevalence of chronic diseases has led the governments to generally emphasize the health- and lifestyle-related behaviors. Chronic diseases are the consequence of inappropriate lifestyle choices which can be prevented through changes in lifestyle (Baum \& Fisher, 2014). Statistics suggest that $70 \%$ of diseases and $53 \%$ of deaths are closely associated with inappropriate lifestyle (Kalroozi, Pishgooie, Taheriyan, Khayat, \& Faraz, 2015). Earlier, special clinical care has been provided by skilled healthcare professionals to control illnesses. However, nowadays, improvement cannot be reached unless taking serious self-care actions to promote health and prevent diseases (Mahmoudi, Karimlou, Sajadi, \& Mahmoudi, 2014). Health-promoting programs can improve individuals' biopsychological development, and reduce treatment costs, with emphasis on preventing health issues and increasing peoples' satisfaction and facilitating access to care and services (Fertman, Allensworth, \& Auld, 2010). For this reason, the focus of healthcare providers has changed from the treatment of the disease to improving lifestyle and eliminating factors that hurt human health (Mahmoudi et al., 2014).

Treating at-risk patients may have no significant impact on the health of society; however, a change in a risk factor, if it is only insignificant clinically at the individual level, can broadly impact on the outbreak of a disease or incidence of a problem (Baum \& Fisher, 2014). Healthy lifestyle reduces the incidence and severity of chronic diseases (Hosseini et al., 2012). Health-promoting lifestyle and self-care can increase patients' control of their daily activities, which will improve their social performance, quality of life, and survival (Shahbaz \& Hemmati-Maslakpak, 2017). Community health nurses manage patients in different environments, perform their activities at three levels of prevention, and play an important role in identifying health problems in self-care. In addition, attention to the health status of patients and families at home, providing the required nursing care and essential education, and referral to health centers in necessary situations, can empower people in taking responsibility of their health. This will reduce the need for hospital care and increase community participation in healthcare (Ministry of Health and Medical Education, 2011).

\section{Materials and Methods}

This predictive correlational- study examined 200 patients with heart failure referring to the heart clinics of Hazrate Rasoul, Firoozgar, and Firoozabadi hospitals affiliated to Iran University of Medical Sciences, in 2018.

The subjects were selected by stratified proportion to size sampling method; the hospitals mentioned above were considered as strata; then, the sample size was determined according to the daily clients of each hospital. The ratio of the patients was 10,8 , and 2 in the three hospitals, respectively; the sample from each hospital was determined, accordingly.

The inclusion criteria were the diagnosis of heart failure with an ejection fraction rate of $\leq 40 \%$, the age of $\geq 18$ years, the lack of speech problems and complications hindering answering the questionnaire. After obtaining permission from the Ethics Committee of Iran University of Medical Sciences, the purpose of the study was explained to the participants, and they were assured of the confidentiality of their personal information. The consent form was obtained; finally, data collection was accomplished at appropriate times and places (waiting time for visits in clinics). Sampling was continuously conducted in different weekdays. Information about the diagnosis of disease, the percentage of ejection fraction, the ability to perform work and activity, the severity of heart failure, and the cause of heart disease were also extracted from the outpatient records.

The data gathering tools were a demographic questionnaire, the Health Promoting Lifestyle Profile II (HPLPII), and the European Heart Failure Self-Care Behavior (EHFScB). Demographic characteristics questionnaire included age, gender, marital status, ejection fraction percentage (centricular discharge fraction [\%]), underlying illnesses, smoking, etc.

HPLPII contains 52 questions with a 4-point Likerttype scale ( $1=$ never, $2=$ sometimes, $3=$ often, $4=$ most of the times). This questionnaire measures the health-promoting lifestyle in 6 dimensions of nutrition, physical activity, health responsibility, spiritual growth, interpersonal communication, and stress management. Its minimum and maximum obtainable scores are 52 and 208, respectively. The score of each subscale is the sum of the scores given to answers. The total score is obtained from the responses to 52 questions. Higher scores represent better health-promoting lifestyle (Pender et al., 2015; Walker, Sechrist, \& Pender, 1987). The validity and reliability of the Persian version of HPLPII have been 
confirmed. The Cronbach's alpha coefficient for the total scale was 0.82 , and it was $0.64-0.91$ for the subscales (Mohammadi Zeidi et al. 2012).

EHFScB is specified for people with heart failure. This questionnaire was introduced by Jaarsma et al. (2003) and consisted of 12 items. The response of each item is based on a 5-point Likert-type scale ranging from "never" (rating: 1) to "always" (rating: 5). To calculate the total score of the questionnaire, the scores of all the items in the questionnaire are summed up. The obtainable score of this questionnaire ranges from 12 to 60 . Lower scores represent better self-care (scores: 12 to 28: good, 29 to 44: moderate, and 45 to 60: weak) (Jaarsma et al. 2003). In Iran, the validity of the questionnaire has been confirmed through content validity (Momeni et al. 2013) and its reliability has been examined by Cronbach's alpha coefficient (Shojaei et al. 2009).

The reliability of this tool has been reported equal to 0 . $68 \%$ by the Cronbach's alpha coefficient method in Shojaei et al. (2009). The collected data were analyzed in SPSS. Frequency distribution tables, and mean and standard deviation were used to describe the qualitative and quantitative data, respectively. Correlation coefficient and multiple linear regression tests were also used. The significance level was set at 0.05 , for all the tests. To determine the reliability of self-care behavior questionnaire, internal consistency was used, and Cronbach's alpha coefficient was calculated in 20 patients with heart failure. Cronbach's alpha coefficient for the health-promoting lifestyle questionnaire was 0.94 , and for self-care behavior questionnaire 0.73 . These patients were excluded from the study.

\section{Results}

Table 1 presents the frequency distribution of demographic characteristics and disease information in the studied subjects. The Mean \pm SD age of the subjects was $64.68 \pm 12.47$ years, the Mean \pm SD duration of the disease was $6.53 \pm 8.41$ years, and the Mean \pm SD ejection fraction was $30.39 \pm 9.49$. The Mean \pm SD score of health-promoting lifestyle was $120.83 \pm 23.13$, which was lower than the median tool score of 130 . To compare health-promoting lifestyle aspects, based on the Likert-type scale, ranging from 1 to 4, physical activity with the mean score of 1.47 was the lowest, and nutrition with the mean score of 2.84 had the highest value (Table 2).

There was a significant relationship between healthpromoting lifestyle and self-care behaviors $(\mathrm{P}<0.001)$. Pearson's correlation coefficient indicated a significant difference between the scores of all aspects of healthpromoting lifestyle and self-care behaviors' score; indicating that by increasing the score of each subscale, self-care score increased $(\mathrm{P}<0.001)$ (Table 3). To predict self-care behaviors, multiple linear regressions were used. The dimensions of health responsibility, physical activity, and nutrition were significant in the regression model, which means that the health responsibility variable with a coefficient of 0.4 had the most effective role in the prediction of self-care behavior of patients with heart failure (Table 4).

\section{Discussion}

The obtained results suggested that the health-promoting lifestyle in patients with heart failure was less than the average. A study on health-promoting behaviors in women with heart failure demonstrated that health-promoting behaviors were less than average (Hosseini et al. 2016); which is consistent with our results. In another study on the relationship between lifestyle and self-efficacy in patients with heart failure, the average score of lifestyle was reported as 54.45; i.e. moderate and was not consistent with our findings (Babaei \& Boroumand 2017). Other studies with different research populations have achieved similar results. Enjezab et al. (2012) identified health-promoting behaviors in middle-aged women in Yazd and Rashidi \& Bahrami (2015) examined health-promoting lifestyle in the elderly in Isfahan; they concluded that the mean value of a health-promoting lifestyle is less than the average (Enjezab et al. 2012; Rashedi \& Bahrami 2015).

Another study reported a higher than average healthpromoting lifestyle value in women with fibromyalgia syndrome (Beal, Stuifbergen \& Brown, 2009). Findings of this study confirmed that among the dimensions of health-promoting lifestyle, physical activity with the Mean \pm SD value of $1.47 \pm 0.58$ had the lowest, and nutrition with the Mean \pm SD value of $2.84 \pm 0.61$ had the highest score; these data are not far from expected according to the type of disease of the studied units. A study which examined health-promoting behaviors in patients with chronic diseases and its related factors; the highest score belonged to nutrition $(2.79 \pm 0.51)$ and the lowest score to physical activity $(1.95 \pm 63)$. This finding is consistent with the present study (Siboni Khatooni \& Atashi, 2018). In another study, the highest score was related to spiritual growth and the lowest to physical activity (Enjezab et al. 2012). Another study indicated that interpersonal communication had the highest, and physical activity had the lowest scores (Hosseini et al. 2016; Rashedi \& Bahrami 2015). The desirability of interpersonal communication 
Table 1. Frequency distribution of demographic characteristics and disease characteristics of the subjects

\begin{tabular}{|c|c|c|c|c|c|c|c|}
\hline \multicolumn{2}{|c|}{ Variable } & \multirow{3}{*}{$\begin{array}{c}\text { No. } \\
117 \\
83\end{array}$} & \multirow{3}{*}{$\begin{array}{c}\% \\
58.5 \\
41.5\end{array}$} & \multicolumn{2}{|r|}{ Variable } & \multirow{2}{*}{$\begin{array}{l}\text { No. } \\
183\end{array}$} & \multirow{2}{*}{$\begin{array}{c}\% \\
91.5\end{array}$} \\
\hline Condor & Male & & & & City & & \\
\hline vetiver & Female & & & Livis piace & Village & 17 & 8.5 \\
\hline \multirow{5}{*}{ Age,y } & $50<$ & 25 & 12.5 & \multirow{5}{*}{$\begin{array}{l}\text { Duration of } \\
\text { disease, y }\end{array}$} & $1<$ & 66 & 33 \\
\hline & $50-59$ & 45 & 22.5 & & $1-4$ & 46 & 23 \\
\hline & $60-69$ & 52 & 26 & & $5-9$ & 30 & 15 \\
\hline & $70-79$ & 50 & 25 & & $10-14$ & 28 & 14 \\
\hline & $80>$ & 28 & 14 & & $15 \geq$ & 30 & 15 \\
\hline \multirow{4}{*}{ Marital status } & Single & 6 & 3 & \multirow{4}{*}{$\begin{array}{l}\text { High blood } \\
\text { lipid control } \\
\text { methods }\end{array}$} & Blood lipid-lowering drugs & 25 & 39 \\
\hline & Married & 133 & 66.5 & & Observing the diet & 6 & 9.4 \\
\hline & Divorced & 12 & 6 & & None & 5 & 7.8 \\
\hline & Widower & 49 & 24.5 & & both & 28 & 43.8 \\
\hline \multirow{5}{*}{ Education } & Literacy & 108 & 54 & \multirow{5}{*}{ Admissions } & Once & 46 & 42.6 \\
\hline & $\begin{array}{c}\text { Secondary } \\
\text { school }\end{array}$ & 44 & 22 & & Twice & 36 & 33.3 \\
\hline & Diploma & 34 & 17 & & 3 times & 22 & 20.4 \\
\hline & $\begin{array}{l}\text { College } \\
\text { graduate }\end{array}$ & 6 & 3 & & 5 times & 1 & 0.9 \\
\hline & $\begin{array}{l}\text { Under- } \\
\text { graduate and } \\
\text { higher }\end{array}$ & 8 & 4 & & 6 times & 3 & 2.8 \\
\hline \multirow{5}{*}{ Occupation } & Unemployed & 35 & 17.5 & \multirow{3}{*}{$\begin{array}{l}\text { Ventricular } \\
\text { discharge } \\
\text { fraction (\%) }\end{array}$} & $5-20$ & 23 & 11.5 \\
\hline & housewife & 81 & 40.5 & & $20-30$ & 49 & 24.5 \\
\hline & Freelance & 35 & 17.5 & & $30-40$ & 128 & 64 \\
\hline & Employee & 45 & 22.5 & \multirow{2}{*}{$\begin{array}{c}\text { Cause of } \\
\text { heart disease }\end{array}$} & Ischemic & 41 & 20.5 \\
\hline & Retired & 4 & 2 & & Non-ischemic & 159 & 79.5 \\
\hline \multirow{3}{*}{ Economic status } & Good & 17 & 8.5 & \multirow{3}{*}{ Smoking } & Yes & 32 & 16 \\
\hline & medium & 91 & 45.5 & & No & 156 & 78 \\
\hline & Weak & 92 & 46 & & Quitted & 12 & 6 \\
\hline \multirow{2}{*}{$\begin{array}{l}\text { Heart failure in } \\
\text { first-degree } \\
\text { relatives }\end{array}$} & Yes & 89 & 44.5 & \multirow{2}{*}{ Insurance } & Yes & 186 & 93 \\
\hline & No & 111 & 55.5 & & No & 14 & 7 \\
\hline \multirow{5}{*}{$\begin{array}{l}\text { Underlying } \\
\text { disease }\end{array}$} & $\begin{array}{l}\text { High blood } \\
\text { pressure } \\
\text { High blood } \\
\text { lipids }\end{array}$ & 123 & 61.5 & \multirow{5}{*}{$\begin{array}{l}\text { Daily activi- } \\
\text { ties }\end{array}$} & \multirow{3}{*}{ Mild limitation } & 74 & 37 \\
\hline & Diabetes & 72 & 36 & & & 57 & 205 \\
\hline & Asthma & 12 & 6 & & & & \\
\hline & Kidney failure & 21 & 10.5 & & \multirow{2}{*}{ Notable Limitation } & \multirow{2}{*}{55} & \multirow{2}{*}{27.5} \\
\hline & Other cases & 15 & 7.5 & & & & \\
\hline Alcohol & Yes & 5 & 2.6 & & Class I & 77 & 38.5 \\
\hline consumption & No & 185 & 97.4 & $\begin{array}{l}\text { The sever- } \\
\text { ity of heart }\end{array}$ & Class II & 54 & 27 \\
\hline History of & Yes & 108 & 54 & failure & Class III & 55 & 27.5 \\
\hline admission & No & 92 & 46 & & Class IV & 14 & 7 \\
\hline
\end{tabular}


Table 2. Numerical indicators of health-promoting lifestyle in patients with cardiac failure

\begin{tabular}{ccccc}
\hline Numerical indicators & Min. & Max. & Mean \pm SD & The Scale of 1 to 4 \\
\hline Spiritual growth & 9 & 36 & $21.3 \pm 6.48$ & Mean \pm SD \\
\hline Health responsibility & 9 & 36 & $20.83 \pm 6.47$ & $2.36 \pm 0.72$ \\
\hline Physical activity & 8 & 28 & $11.79 \pm 4.89$ & $2.31 \pm 0.71$ \\
\hline Nutrition & 13 & 34 & $25.59 \pm 5.29$ & $1.47 \pm 0.58$ \\
\hline Interpersonal communication & 9 & 36 & $25.32 \pm 5.62$ & $2.84 \pm 0.61$ \\
\hline Stress management & 8 & 27 & $16.01 \pm 3.63$ & $2.81 \pm 0.62$ \\
\hline Health promoting lifestyle & 68 & 182 & $120.83 \pm 23.13$ & $2 \pm 0.45$ \\
\hline
\end{tabular}

Client- Centered Nursing Care

among the elderly may be due to the influence of religion. Religion can positively impact loneliness feelings, managing stress, positive and constructive interactions, adapting to different conditions, and searching for a meaning in life (Bahrami 2009).
The difference in the status of health-promoting behaviors in different societies is due to the impact of individual, socioeconomic, and environmental factors that affect people's health; it can be the reason for incongruities between the results of the two studies.

Table 3. Correlation between health-promoting lifestyle and self-care behaviors in patients with cardiac failure

\begin{tabular}{ccc}
\hline Health-Promoting Lifestyle & \multicolumn{1}{c}{ Self-Care Behavior } \\
\hline Spiritual growth & $P<0.001$ & $r=0.35$ \\
Health responsibility & $P<0.001$ & $r=0.55$ \\
Physical activity & $P<0.001$ & $r=0.33$ \\
Nutrition & $P<0.001$ & $r=0.42$ \\
\hline Interpersonal communication & $P<0.001$ & $r=0.37$ \\
Stress management & $P=0.001$ & $r=0.23$ \\
Health promoting lifestyle & $P<0.001$ & $r=0.55$ \\
\hline
\end{tabular}

Client- Centered Nursing Care

Table 4. Multiple linear regression for the prediction of self-care behaviors in patients with heart failure

\begin{tabular}{ccccc}
\hline Independent Variables & Model Coefficient & SD & Test Statistic & P \\
\hline Spiritual growth & 0.02 & 0.02 & 0.24 & 0.80 \\
Health responsibility & 0.58 & 0.4 & 5.60 & $<0.001$ \\
\hline Physical activity & 0.29 & 0.158 & 2.31 & 0.021 \\
Nutrition & 0.46 & 0.273 & 4.36 & $<0.001$ \\
\hline Interpersonal communication & 0.10 & 0.066 & 0.90 & 0.36 \\
\hline Stress management & -0.27 & -0.10 & 0.14 & 0.14 \\
\hline
\end{tabular}


The Mean \pm SD value of self-care behaviors was $34.8 \pm 9.03$; i.e. at moderate level. In line with the obtained results, Bagheri, saweh \& Ashketorab (2016) indicated that the self-care behaviors of patients with heart failure were at an average level (Mean=39.54) (Bagheri saweh \& Ashketorab, 2016). Mansouri et al. (2018) and Shahbaz \& Hemmati-maslakpa (2017) studied self-care behaviors in patients with heart failure. They reported the mean score of self-care behaviors as 44.26 and 45.59, respectively (Mansouri et al. 2018; Shahbaz \& Hemmati-Maslakpak 2017), that is consistent with our results. In a study in the United States, it was demonstrated that most women and men with heart failure fail to continuously conduct self-care behaviors. The Mean \pm SD score of self-care in the subjects under the study was $62.3 \pm 19$ (Heo et al., 2008).

Contrary to the present study, self-care behaviors in patients with heart failure have been reported at a reasonable level. In a study on patients with heart failure, the mean score of self-care behaviors was 24.7, which revealed a reasonable level (Peters-Klimm et al. 2013). In another study with a different research population, the same result was achieved. In a study by Bairami et al. (2017) which investigated self-care behaviors in people with hypertension and its relationship with the quality of life, self-care behaviors were reported as appropriate, and the related mean score was 63.5 (Bairami et al. 2017). Another finding of the present research was the relationship between health-promoting lifestyle and its dimensions with self-care behavior. Among the dimensions of health-promoting behaviors, the highest score belonged to health responsibility, and the lowest to stress management. Data on this area are scarce; however, various factors have been reported to influence self-care behaviors in patients. Babaei and Borouman revealed a significant relationship between self-efficacy and healthpromoting behaviors and all of its dimensions (Babaei \& Boroumand 2017).

In other similar studies, there was also a significant relationship between self-care behaviors and the quality of life (Kueh, Morris \& Ismail 2017; Thiel et al. 2017). Abedi et al. (2012) detected a positive and significant correlation between self-efficacy and self-care behaviors in patients with chronic obstructive pulmonary disease; it means when self-efficacy increases, self-care behaviors are improved (Abedi et al. 2014). Seyedoshohadaee et al. (2016) indicated a significant relationship between health literacy and the two dimensions of self-care behaviors, including diet and follow-up of drug regimens (Seyedoshohadaee et al. 2016).
Additionally, in relation to the different dimensions of health-promoting behaviors, health responsibility, physical activity, and nutrition had a significant relationship with self-care behaviors; among those, health responsibility was the most effective one in self-care behaviors. Another study reported a significant relationship between se lf-care behaviors and physical function in patients (LaPier, Cleary \& Kidd, 2009). Furthermore, Sol et al. (2011) examined the relationship between selfefficacy and lifestyle in cardiovascular patients. They indicated that with improvement in physical activity and nutritional habits, the self-efficacy of patients with cardiovascular disease also increased.

A study about the relationship between sources of health control, self-care and adherence to the therapeutic regimen in hypertensive patients revealed a direct relationship between the source of internal health controlincluding nutrition and proper diet, the responsibility to disease, and proper activity- and the patients' self-care behaviors (Taher \& Bayat 2015).

Heart failure is a chronic disease which affects different aspects of life; thus, adopting non-prescriptive strategies, including health-promoting lifestyle and self-care behaviors is necessary, in addition to pharmacotherapies. Due to the low percentage of health-promoting lifestyle in patients with heart failure, it is recommended to conduct a study aimed at investigating the barriers and problems of lifestyle in patients with chronic heart disease, especially those with heart failure. Such data may be beneficial to obtain appropriate strategies to improve and modify patients' health-promoting lifestyle.

\section{Ethical Considerations}

\section{Compliance with ethical guidelines}

Permission of the Ethics Committee of Iran University of Medical Sciences was obtained (Code: IR.IUMS. REC.1396.9511690005) before the initiation of the study. The subjects were assured of the confidentiality of their personal information. Informed consent was obtained from all the participants.

\section{Funding}

The present paper was extracted from the MSc. thesis of the first author, Department of Community Health Nursing, School of Nursing and Midwifery, Iran University of Medical Sciences. 


\section{Authors' contributions}

Conceptualization: Sousan Saadati, Marhamat Farahaninia, Mehri Bozorgnejad; Methodology: Sousan Saadati, Marhamat Farahaninia and Hamid Haghani; Investigation: Sousan Saadati; Writing original draft, Writing-review and editing: Sousan Saadati, Marhamat Farahaninia; and Supervision: Marhamat Farahaninia.

\section{Conflict of interest}

The authors declared no conflicts of interest.

\section{Acknowledgments}

The researchers thank IUMS for its financial support. All the efforts of the professors of the Nursing Faculty of IUMS, the honorable authorities of the heart clinics of the Hazrat Rasoul, Firoozgar, Firoozabadi, affiliated to IUMS, and all the people and patients who helped us with this research are genuinely appreciated.

\section{References:}

Abedi, H. A., et al., 2014. [A survey on the the lifestyle of the heart desease patients after discharge from hospital in urmia seyyed alshohada in 1391 (Persian)]. The Journal of Urmia Nursing and Midwifery Faculty, 11(12), pp. 944-54.

Babaei, S. \& Boroumand, S., 2017. [Relationship between lifestyle and cardiac self efficacy among people with heart failure (Persian)]. Cardiovascular Nursing Journal, 5(4), pp. 36-44.

Bagheri Saweh, M. I. \& Ashketorab, T., 2016. The study of selfcare behaviors and its related factors in patients with congestive heart failure hospitalized in cardiology wards of Tohid Hospital in Sanandaj city. Journal of Nursing, Midwifery and pramedical, 1(3), pp. 1-11. [DOI:10.29252/sjnmp.1.3.1]

Bahrami, F., 2009. [The elderly mental health in the holy Quran (Persian)]. Sālmand, 4(1), pp. 1-5.

Bairami, S., et al., 2017. [Relationship between self-care behaviors and quality of life among hypertensive patients visiting comprehensive health centers in Hamadan, Iran (Persian)]. Journal of Education and Community Health, 4(1), pp. 20-7. [DOI:10.21859/jech.4.1.20]

Bauersachs, J., Butler, J. \& Sandner, P., 2017. Heart Failure, Berlin: Springer. [DOI:10.1007/978-3-319-59659-4] [PMID]

Baum, F. \& Fisher, M., 2014. Why behavioural health promotion endures despite its failure to reduce health inequities. Sociology of Health E Illness, 36(2), pp. 213-25. [DOI:10.1111/14679566.12112] [PMID]

Beal, C. C., Stuifbergen, A. K. \& Brown, A., 2009. Predictors of a health promoting lifestyle in women with fibromyalgia syndrome. Psychology, Health \& Medicine, 14(3), pp. 343-53. [DOI:10.1080/13548500902730093] [PMID]
Khachian, A., et al. 2016. Family-centered education and selfcare behaviors of patients with chronic heart failure. Journal of Client-Centered Nursing Care, 2(3), pp. 177-84. [DOI:10.32598/ jccnc.2.3.177]

Del Gobbo, L. C., et al., 2015. Contribution of major lifestyle risk factors for incident heart failure in older adults: The cardiovascular health study. the Cardiovascular Health Study. Heart Failure, 3(7), pp. 1-9. [DOI:10.1016/j.jchf.2015.02.009] [PMID] [PMCID]

Enjezab, B., et al., 2012. Health promoting behaviors in a population-based sample of middle-aged women and its relevant factors in Yazd, Iran. International Journal of Preventive Medicine, 3(Suppl. 1), pp. S191-8. [PMID] [PMCID]

Fertman, C. I., Allensworth, D. D., Auld, M. E., 2010. What are health promotion programs. In: Fertman, C. I., Allensworth, D. D. \& Auld, E., Eds. Health Promotion programs: From theory to practice (pp. 3-21). San Francisco: Jossey Bass.

Graven, L. J., Grant, J. S. \& Gordon, G., 2015. Symptomatology and coping resources predict self-care behaviors in middle to older age patients with heart failure. Nursing Research and Practice, 2015(840240), pp. 1-8. [DOI:10.1155/2015/840240] [PMID] [PMCID]

Halmo, R., et al., 2015. Self care in patients with chronic hear failure: Pilot study-self care includes problems. Biomedical $\mathrm{Pa}$ pers, 159(1), pp. 124-30. [DOI:10.5507/bp.2013.044] [PMID]

Heo, S., et al., (2008) Gender differences in and factors related to self-care behaviors: a cross-sectional, correlational study of patients with heart failure. International journal of nursing studies, 45(12), pp. 1807-15.

Hosseini, M., et al., 2016. The correlation of inner strength and health promoting behaviors in women with heart failure. Faculty of Nursing of Midwifery Quarterly, 25(91), pp. 9-19. [DOI:10.19082/2810] [PMID] [PMCID]

Hosseini, M., et al., 2012. [Psychometric evaluation of the "Health promoting life style profile 2" (Persian)]. Journal of the Iraninan Institute for Health Sciences Research, 11(6), pp. 849-56.

Jaarsma, T., et al., 2003. Development and testing of the European Heart Failure Self-Care Behaviour scale. European Journal of Heart Failure, 5(3), pp. 363-70. [DOI:10.1016/S13889842(02)00253-2

Kalroozi, F., et al., 2015. Health-promoting behaviours and related factors among nurses in selected military hospitals. Military Caring Sciences, 1(2), pp. 73-80. [DOI:10.18869/acadpub. mcs.1.2.73

Karbaschi, K., Farsi, Z. \& Siadati, S., 2010. [Exploration of the concept of self-care and implications for nurses (Persian)] Journal of Army Nursing Faculty, 9, pp. 13-16.

Kueh, Y. C., Morris, T. \& Ismail, A. A. S., 2017. The effect of diabetes knowledge and attitudes on self-management and quality of life among people with type 2 diabetes. Psychology, Health $\mathcal{E}$ Medicine, 22(2), pp. 138-44. [DOI:10.1080/13548506.2 016.1147055] [PMID]

LaPier, T. K., Cleary, K. \& Kidd, J., 2009. Exercise self-efficacy, habitual physical activity, and fear of falling in patients with coronary heart disease. Cardiopulmonary Physical Therapy Journal, 20(4), p. 5-11. [DOI:10.1097/01823246-200920040-00002] [PMID] [PMCID] 
MacInnes, J., 2013. Relationships between illness representations, treatment beliefs and the performance of self-care in heart failure: A cross-sectional survey. European Journal of Cardiovascular Nursing, 12(6), pp. 536-43. [DOI:10.1177/1474515112473872] [PMID]

Mahmoudi, Z., et al., 2014. [The life stye concepts and approaches (Persian)]. Second Edn. Tehran: Kavosh.

Mansouri, K., et al., 2018. [Self-care status and its related factors in patients with heart failure (Persian)]. Journal of Health and Care, 19(4), pp. 232-41.

Ministry of Health and Medical Education, 2011. [Master's degree curriculum in community health nursing (Persian)]. Tehran: Ministry of Health and Medical Education.

Ministry of Health and Medical Education, 2014. Self-care educational and intelligence package (Persian)]. Tehran: Ministry of Health and Medical Education.

Mohammadi Zeidi, I., Pakpour Hajiagha, A. \& Mohammadi Zeidi, B., 2012. [Reliability and validity of Persian version of the health-promoting lifestyle profile (Persian)]. Journal of Mazandaran University of Medical Sciences, 21(1), pp. 102-13.

Mohseni Pouya, H., et al., 2015. [Relationship between health promoting behaviors and severity of coronary artery stenosis in angiography department in Mazandaran Heart Center (Persian)]. Journal of Mazandaran University of Medical Sciences, 25(130), pp. 19-29.

Momeni, M., et al., 2013. [Self-care behaviors and related factors in patients with heart failure reffering to medical \& educational center of heart in Rasht (Persian)]. Journal of Holistic Nursing and Midwifery, 23(1), pp. 22-9.

Moser, D. K., et al., 2012. Role of self-care in the patient with heart failure. Current Cardiology Reports, 14(3), pp. 265-75. [DOI:10.1007/s11886-012-0267-9] [PMID]

Paulik, E., et al., 2010. Determinants of health-promoting lifestyle behaviour in the rural areas of Hungary. Health Promotion International, 25(3), pp. 277-88. [DOI:10.1093/heapro/ daq025] [PMID]

Pender, N. J., Murdaugh, C. L. \& Parsons, M. A., 2015. Health promotion in nursing practice. Boston: Pearson.

Peters-Klimm, F., et al. 2013. Determinants of heart failure selfcare behaviour in community-based patients: A cross-sectional study. European Journal of Cardiovascular Nursing, 12(2), pp. 167-76. [DOI:10.1177/1474515112439964] [PMID]

Rafieifar, S., Yazdani, S. \& Moghimi, D., 2015. [A guide to empowering families for self-care (Specially for family physician and health team) (Persian)]. Tehran: Mehrravash.

Rashidi, S. \& Bahrami, M., 2015. [Factors related to the health promoting life style among geriatric patients (Persian)]. The Journal of Urmia Nursing and Midwifery Faculty, 13(2), pp. 90-8.

Riegel, B., Lee, C. S. \& Dickson, V. V., 2011. Self care in patients with chronic heart failure. Nature Reviews Cardiology, 8(11), pp. 644-54. [DOI:10.1038/nrcardio.2011.95] [PMID]

Seyedoshohadaee, M., et al., 2016. [The relationship between health literacy and self-care behaviors in patients with type 2 diabetes (Persian)]. Iranian Journal of Nursing Research, 10(4), pp.43-51.
Shahbaz, A. \& Hemmati-Maslakpak, M., 2017. [Relationship of self-care behaviors with hospital readmission in people with heart failure (Persian)]. Cardiovascular Nursing Journal, 6(2), pp. 24-33.

Shojaei, F., et al., 2009. [Self-care behaviors in patients with heart failure (Persian)]. Payesh, 8(4), pp. 361-9.

Siboni, F.S., Khatooni, M. \& Atashi, V., 2018. Health-promoting lifestyle practices among patients with chronic diseases and its related factors. Social Health and Behavior, 1(2), pp. 67-73. [DOI:10.4103/SHB.SHB_29_18]

Sol, B. G., et al., 2011. The effect of self-efficacy on cardiovascular lifestyle. European Journal of Cardiovascular Nursing, 10(3), pp. 180-6. [DOI:10.1016/j.ejcnurse.2010.06.005] [PMID]

Taher, M. \& Bayat, Z. S., 2015. Correlation between compliance regimens with health locus of control in patients with hypertension. Medical Journal of the Islamic Republic of Iran, 29, p. 194. [PMID] [PMCID]

Thiel, D. M., et al., 2017. Association between physical activity and health-related quality of life in adults with type 2 diabetes. Canadian Journal of Diabetes, 41(1), pp. 58-63. [DOI:10.1016/j. jcjd.2016.07.004] [PMID]

Vaillant-Roussel, H., et al. 2014. Patient education in chronic heart failure in primary care (ETIC) and its impact on patient quality of life: Design of a cluster randomised trial. BMC Family Practice, 15, p. 208. [DOI:10.1186/s12875-014-0208-3] [PMID] [PMCID]

Walker, S. N., Sechrist, K. R. \& Pender, N. J., 1987. The healthpromoting lifestyle profile: Development and psychometric characteristics. Nursing Research, 36(2), pp. 76-81. [DOI:10.1097/00006199-198703000-00002]

Zamanzadeh, V., et al., 2012. Self-care behaviors among patients with heart failure in Iran. Journal of Caring Sciences, 1(4), pp. 209-14. [DOI:10.1155/2013/492729] [PMID] [PMCID] 
This Page Intentionally Left Blank 